\title{
MILK Symposium review: Improving the productivity, quality, and safety of milk in Rwanda and Nepal*
}

\author{
A. De Vries, ${ }^{1} \dagger \odot$ K. E. Kaylegian, ${ }^{2} \odot$ and G. E. Dahl ${ }^{1} \odot$ \\ ${ }^{1}$ Department of Animal Sciences, University of Florida, Gainesville 32611 \\ 2Department of Food Science, The Pennsylvania State University, University Park 16802
}

\begin{abstract}
Dairy production plays an important role in the lives of many people in Rwanda and Nepal. The aim of the Feed the Future Innovation Lab for Livestock Systems (LSIL; Gainesville, FL) is to introduce new locationappropriate technologies and to improve management practices, skills, knowledge, capacity, and access to inputs across livestock value chains in developing countries such as Rwanda and Nepal. To assist LSIL, our first aim was to describe gaps in the management of cows and in milk processing that constrain milk quality and quantity in Rwanda and Nepal. Our second aim was to describe training-of-trainers workshops in both countries as an initial response to the findings from the first objective. We conducted literature reviews and did rapid needs assessments in both countries. The literature reviews revealed similar aspects of the challenges of smallholder crop-livestock mixed farming systems in both countries. Many farms are struggling with feed quality, reproduction, and health of dairy cows. Milk production per cow and quality is often low. Fresh milk is collected by milk collection and cooling centers. Hygiene and milk processing capability and shelf life of products can be improved. Local rapid needs assessments were conducted in 2016 (Rwanda) and 2017 (Nepal) through visits to farms, milk collection and chilling centers, and processing plants, and through discussions with local dairy officials. The assessments supplemented and completed our understanding of stakeholders' needs in management and processing of milk. Limiting factors to improving the productivity, quality, and safety of milk in Rwanda and Nepal were a combination of sometimes limited knowledge in areas such as feeding, mastitis control, and hygiene, and a

Received February 1, 2020.

Accepted May 11, 2020.

*Presented at the MILK Symposium: Improving Milk Production, Quality, and Safety in Developing Countries at the ADSA Annual Meeting, Cincinnati, Ohio, June 2019.

†Corresponding author: devries@ufl.edu
\end{abstract}

lack of access to resources such as quality feeds, transportation, and cooling that hindered implementation of existing knowledge. Training-of-trainers workshops in milk processing and hygiene were developed and given in Rwanda and Nepal based on the rapid needs assessments, and these were well received. We concluded that Rwanda and Nepal both have smallholder dairy farms that often face similar challenges such as lack of quality feeds, needs for basic dairy management education, low cattle productivity, and undesirable milk quality. Training-of-trainers programs to address these basic issues may be successful. Continued improvements in the dairy value chain depend on available resources for education.

Key words: smallholder, quality, productivity, training

\section{INTRODUCTION}

Animal-source foods play a critical role in reducing poverty and improving nutritional and food security, gender equity, livelihoods, and health in many developing countries (WHO, 2014; Adesogan et al., 2019). In 2015, the US Agency for International Development awarded the University of Florida funds to establish the Feed the Future Innovation Lab for Livestock Systems (LSIL). The LSIL aims to improve the nutrition, health, and incomes of vulnerable populations, particularly pregnant and lactating women and children under 2 yr old, by sustainably increasing livestock productivity and marketing and consumption of animal-source foods. The aim of LSIL is to introduce new location-appropriate technologies by improving management practices, skills, knowledge, capacity, and access to quality inputs across livestock value chains. Another aim is to support the development of a policy environment that fosters sustainable intensification and increased profitability of smallholder livestock systems. This 5-yr initiative (October 2015 to September 2020) has 6 target countries, including Rwanda in East Africa and Nepal in Central Asia.

Dairy production plays an important role in providing animal-source foods and in the cultural identity of 
many people in Rwanda and Nepal. The productivity of cattle, milk quality, hygiene of milk collection and processing capability, and shelf life of products are typically considered areas needing improvement. Part of the LSIL mission is to improve the productivity, quality, and safety of milk in Rwanda (Africa) and Nepal (Asia). Although these 2 countries are more than 6,000 $\mathrm{km}$ apart, their dairy industries have much in common.

This review has 3 objectives. First, we describe gaps in feeding and management of cows and in milk processing, that constrain milk quality and quantity in Rwanda and Nepal based on the available written literature. Second, we describe the implementation and outcomes of rapid needs assessments conducted in both countries to supplement findings from the literature. Third, we describe the implementation and outcomes of training-of-trainers workshops conducted in Rwanda and Nepal as a first response to the findings from the first 2 objectives. We conclude with recommendations.

\section{METHODOLOGY AND RESULTS}

\section{Literature Review Methodology}

Before the rapid needs assessments that were conducted on location in both countries, we conducted literature reviews on the gaps in feeding and management of dairy cows and in milk processing that constrain milk quality and quantity. Information was obtained from peer-reviewed literature, internet searches related to "dairy," "Rwanda," and Nepal," and from LSIL partners in Rwanda and Nepal who are familiar with the local dairy industry. The results of these literature searches, described in Dahl and Hendrickx (2018) for Rwanda and in De Vries and Kaylegian (2017) for Nepal, are briefly presented for each country.

\section{RWANDA}

\section{Literature Review}

The incidence of chronic child undernutrition and stunting was 37\% in Rwanda in 2015 (World Food Programme, 2016). This current high stunting rate emphasizes the need to incorporate animal-source foods in the diet of children as well as adults. Dairy production is also the largest livestock-related subsector of agriculture in Rwanda. For these reasons, the Rwandan government has emphasized growth of the dairy sector as a key mechanism to improve access to animalsource foods (IFAD, 2016). Consequently, the Girinka program ("one cow per poor family"; Ezeanya, 2014) was developed to address a particularly vulnerable segment of the population: families with limited capacity to access animal-source foods (Rwandan Government Board; http://www.rgb.rw/index.php?id = 171). Such interventions need to be cognizant of environmental concerns and the fact that Rwanda has the highest human population density in sub-Saharan Africa (SYB, 2015).

The typical livestock production system is the smallholder crop-livestock mixed farming, with the average smallholder farmer having 1 to 3 cows (Bishop and Pfeiffer, 2008; Kamanzi and Mapiye, 2012). Milk is often collected daily by local milk collection and cooling centers, from where it is distributed to retail outlets. Improved breeds account for $28 \%$ of the total cow population and contribute $82 \%$ of the total milk produced (MINAGRI, 2013). The local Ankole breed has low milk production with an average mean milk yield of 1.33 to $4.58 \mathrm{~L} / \mathrm{d}$ (Klapwijk et al., 2014). The Girinka program has increased the penetration of improved or "exotic" genetics, mostly Holstein-Friesian, which when properly managed can produce greater yields and are more efficient (IFAD, 2016; McMahon, 2016); however, feed resources in particular are limited in this area.

A lack of understanding related to the impact of mastitis on milk yield and quality hampers efforts to improve yields (Nedhetuye, 2019). This will require training on the importance of milking hygiene, barn cleanliness, and milking equipment sanitation to harvest high-quality milk. Most of the milk transport to milk collection centers (MCC) takes an extended period of time and lacks refrigeration (IFAD, 2016), which translates to greater potential for bacterial growth and spoilage. In the case of locally marketed milk, pasteurization is not common, even if cooling occurs.

Strategies needed for growth of the dairy sector include improved milk production and marketing systems, policy environments, and institutional frameworks (MINAGRI, 2013). Improved competitiveness of the Rwandan dairy sector will greatly depend on the productivity of its dairy cows and the quality of the milk produced. Personnel at MCC, extension agents, milk processors, and community animal health workers have access to farmers but are not necessarily aware of the role that feeding and management play in animal performance and production of a healthy dairy product, nor do they all have the curriculum to train farmers.

\section{Rapid Needs Assessment in Rwanda}

A rapid needs assessment was conducted in Rwanda in 1 wk in December 2016 by author GED and a colleague (Dahl and Hendrickx, 2018). The team had experience in dairy management and processing. They worked together with a local dairy expert who accompanied the team. This rapid assessment consisted of visits to 
3 farms, 3 feed mills, 2 MCC, and 1 processing center. The locations of these visits were in the Gicumbi district, Bugesera, Eastern Province; Rwamagana district, Kayonza district, Rwamagana; Kamonyi, and Kigali. All locations were in the eastern and central regions of Rwanda. Each visit consisted of a tour and discussions with local dairy stakeholders. In addition, the team met with dairy officials from the Rwanda Agricultural Board, University of Rwanda, and Land O' Lakes. These visits and meetings were used to assess current practices and verify the findings of the literature review conducted before the rapid needs assessment, as well as to identify key stakeholders. The assessment resulted in a more holistic view of the Rwandan dairy sector and elucidation of needs that could be partially addressed with training programs in the short term. The main findings are as follows.

Farms. The quality and availability of forage as well as the occurrence of nematodes are a challenge during the dry season. Access to concentrate feeds is good, but the understanding of the relationship of a balanced feeding program and overall animal performance needs to be improved. Dairy cattle housing is sometimes nonexistent and there may be limited shade available to the cows. When there is housing, soft bedding material may be absent. Feed is not always available and cows often have low body condition scores. Overall, the feeding of cows is suboptimal, which reduces milk production and decreases processing quality. Water is not available for cows ad libitum, depending on access to the source and lack of knowledge about the importance of continuous water availability. Tick-borne diseases such as East Coast Fever are considered a main health problem; therefore, regular treatment and spraying against external parasites is done. Mastitis remains a major problem, with almost $75 \%$ clinical occurrence on these farms, consistent with recent broader estimates of mastitis incidence in Rwanda of $70 \%$ at the herd level and $66 \%$ at the cow level (Ndahetuye, 2019; Ndahetuye et al., 2019). In general, we found there to be limited knowledge concerning AI and reproductive management optimization.

Feed Mills. Availability of feed ingredients is sometimes limited. The challenge is that most feeds are imported from outside Rwanda. Available feed ingredients are expensive and often of low quality. High prices limit the use of feed supplements by local dairy farmers. There is often a weak response to the addition of feed supplements by native animals, which is further aggravated by the lack of a recording system with regard to cattle production and breeding. Feed mills estimate that milk production must be at least $20 \mathrm{~L} / \mathrm{d}$ for supplementation with concentrate to be profitable.
MCC. Milk collection centers may be cooperatives or private enterprises. Farmers do not chill their milk at the farm; rather, milk is chilled after reaching the MCC. The greatest distance milk travels is $10 \mathrm{~km}$, taking 60 to 90 min to transport to an MCC. Temperature management during transport is an obvious area of concern. Dairy milk collected at an MCC is typically tested for alcohol, organoleptic quality (taste, smell), visual check for floaters, specific gravity, and temperature. A sample of collected milk is tested for antibiotics on the whole tank as a bulk indicator for antibiotic residues. Testing results in little milk being rejected. There are cold chain issues related to the MCC, specifically after they supply wholesalers or retailers. These include lack of cooling on the farm, uninsulated transport vessels, and extended time to transport the milk from the farm to the MCC. The high prevalence of mastitis on farms hampers the quality of milk. The MCC may conduct testing of the milk of individual cows to identify cows with high SCC in the rare case that milk is rejected.

Milk Processing. Milk quality has been improved by investments in stainless and aluminum cans in addition to insulated tankers to transport the milk from the MCC to processing plants. Milk may be pasteurized, processed into yogurt, butter, fresh cream, low fat milk, and mozzarella cheese. Cultural barriers hinder the consumption of milk products, such as the idea is that yogurt is for children only. Home-produced milk sold through informal markets is less expensive than processed milk from MCC.

Dairy Organizations. Mastitis is considered a major problem by local stakeholders. There is a need to continue building the capacity of MCC with regard to mastitis and technical training to improve the milk value chain. There is little survey information on the antibiotic residue load in milk overall, although some evidence suggests that antimicrobial residues in milk are uncommon (Ndahetuye, 2019). However, concern exists over giving too much responsibility to MCC veterinarians, who are conflicted because they are both distributing the antibiotics and testing the milk. Often, the same veterinarian who sells the antibiotic is the one accepting the milk at the MCC the next day. Increased capacity is needed to test for antibiotic residues in animal products, especially fresh milk. Antimicrobial resistance is a big area of interest in Rwanda following the global guidelines from the World Organization for Animal Health. There is also a need to improve protocols for milk quality testing at the MCC, along with additional training on milk handling.

Capacity development is a key interest of the dairy officials. This includes more training for dairy farmers, extension workers, veterinarians, and dairy value chain 
policy development. For example, veterinary students showed great interest in postgraduate training, including milk harvest procedures, mastitis control, AI and reproductive management, and dairy nutrition. More broadly, there is a need to improve general recordkeeping on farms and the use of that information for management decisions. Lack of funding for capacity building is a major limiting factor.

Officials also expressed a desire to improve the genetic base of the cattle and to highlight the advantages of the use of improved dairy cattle over, for example, crop production. Cattle can add value from forage produced on a small acreage by conversion of fodder and grasses to highly nutritious dairy products, which is common in Rwanda (Appendix 1). There is a need for Rwandan dairy producers to consider their animals as an enterprise and conduct animal rearing or husbandry in a market-oriented manner, but for that to occur more training efforts are needed.

Recommendations from the Rapid Needs Assessment. From the various visits and the stakeholders interviewed, the following 4 major needs were identified. (1) Develop a curriculum and training for veterinary students and practitioners regarding cow nutrition, reproductive management, and milk harvest protocols, especially with an emphasis on the practical management appropriate to Rwanda. Mastitis prevention and treatment training are critically needed, as further development of domestic and export markets will be limited by milk quality. (2) Improve protocols for milk testing at the MCC, along with additional training on milk handing. There may also be a way to introduce pasteurization at the MCC. This would be a significant opportunity to improve the wholesomeness and nutritional quality of milk. (3) Further develop trainings on dairy nutrition for smallholders to increase yields and animal health and productivity is needed. It was clear that the nutrition of many cows in the Girinka program was insufficient, and the sustainability of a reproductive improvement program is likely limited because of reproductive failures due to anovulation. A survey of the program to determine the number of cows that actually calve more than once and continue to provide milk to the family is an important next step. (4) Improve accurate data recording on health and productivity of cattle so that results of changes in practices can be better quantified.

\section{Training of Trainers in Rwanda}

Training Program Design. Based on the needs assessment report, a farm assessment tool was developed to support on-farm training in dairy management and milk collection on smallholder farms in Rwanda. The training had 3 course objectives. On completion of the module, participants were expected to (1) conduct a smallholder dairy farm assessment using the farm diagnostic tool; (2) provide the farmer (on the spot) with recommendations for improvement in a structured way; and (3) produce a standard report for the farm, documenting findings and recommendations and next steps. The report can then be used for monitoring progress over time and as a benchmark for future assessments. Training information was presented at 2 locations in August 2018 and included both classroom delivery and on-farm evaluation. Each session lasted 2 d. Training was targeted at government and private practice veterinarians, MCC managers, and University of Rwanda faculty. Particular emphasis in the training was placed on the impact of nutrition and management on milk quality and suitability for processing. Each participant was provided a copy of the assessment tool for future use, along with the slide sets used for training as an additional support tool for subsequent trainings they would deliver.

Results of Trainings and Impacts. Each training session had a different group of participants, with the one in Musanze in northern Rwanda being heavily skewed toward MCC managers and personnel $(\mathrm{n}=22)$ and the second at Nyamata in central Rwanda being government and private veterinarians and university faculty $(\mathrm{n}=20)$. The assessment tool was well accepted and understood by participants, and functionality at the farm level was good. Participants engaged with the farmers at all testing sites $(\mathrm{n}=4)$ and gained perspective on the limitations of the tool at the farm level. All participants indicated that they would use the tool in their own field work, but the challenge identified to adoption was the limited number of, and power of, laptops or tablets to use in training. This was viewed as less of a problem for the MCC personnel because the MCC had greater resources to adopt the use of the tool in the field.

\section{NEPAL}

\section{Literature Review}

Dairy farming affects the livelihood of many rural people. Nepal's dairy cattle population is estimated to be 7.27 million cows and 5.24 million buffaloes (MoLD, 2016). Only $13 \%$ of cattle and $26 \%$ of buffaloes are improved breeds (NARC, 2016). The average farm size is small (0.7 ha; CBS, 2013). Table 1 gives an overview of the typical farms in different regions of Nepal. A decade ago, total milk production in the country was about 1,734,000 t, of which milking buffaloes contributed about $70 \%$ and dairy cows contributed about $30 \%$ 
Table 1. Characteristics of the main dairy production systems prevailing in the 3 main milk production areas in Nepal (Source: Sharma and Banskota, 2002)

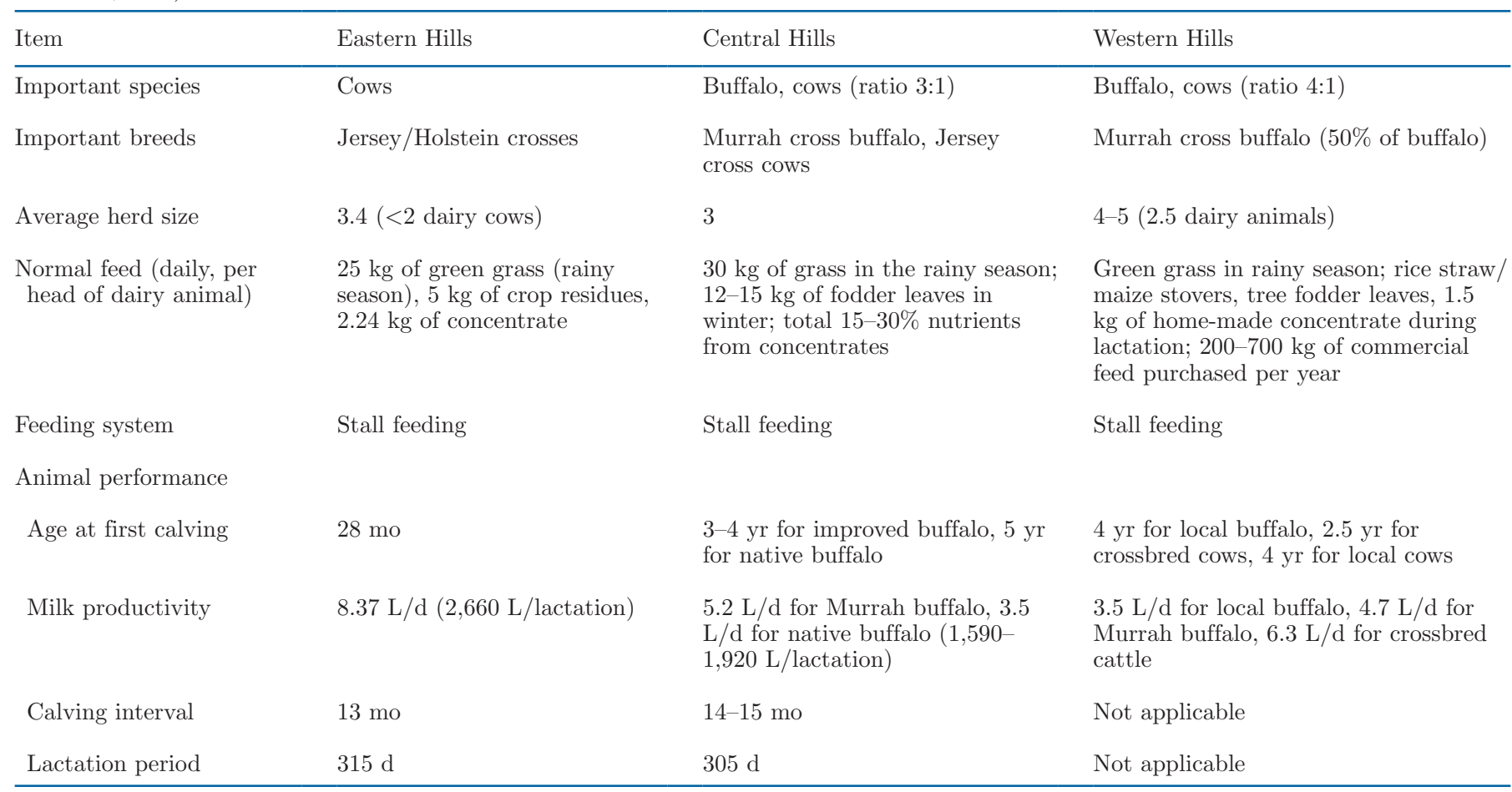

(MoAD, 2012). Dairy farming in Nepal is predominantly in the smallholder production system. Almost $90 \%$ of the total milk received by the formal dairy processing industry in the country is estimated to come through dairy cooperatives (MoLD, 2016).

Nepal produces about one-third less feed than it needs for its livestock (Pande, 1997). Production of crop residue is sufficient to meet the feed demand, but the more nutritious green fodder and concentrates are greatly lacking (Pande, 1997). Although limited supplies of feed are apparent, there are also limitations to the efficient utilization of byproducts and fodder resources. Cows are typically housed in sheds, and milking is mostly done by hand into a bucket. Lack of farm sanitation and unhygienic milking practices are the primary risk factors for the high prevalence of mastitis in Nepal (Dhakal et al., 2007).

Animal-source foods including milk commonly have a poor safety record in Nepal (Arjyal et al., 2004; Maharjan et al., 2006; Adhikari et al., 2012; Shrestha and Bindari, 2012; Upadhaya et al., 2012). Dairy product safety concerns have become one of the priority areas of the government of Nepal.

The problem with milk quality is mainly due to milk being contaminated at the farm level due to manure and lack of personal hygiene (Sharma and Banskota, 2002; FAO, 2010). Cleanliness of the milking vessels, storage vessels, and transport cans is often not satisfac- tory (FAO, 2010). Farmers mainly use only plain water or, in a few cases, detergents or ash to clean utensils. There is little consistency in the use of cleaning and sanitizing chemicals. Many of these problems exist because of lack of training. In some cases, adulteration of milk is done with extraneous substances such as sodium bicarbonate, sugar, and urea, which are added to the milk to prevent spoilage and extend the shelf life (Samarth-Nepal, 2016)

\section{Rapid Needs Assessment in Nepal}

A rapid needs assessment was conducted in Nepal in 1 wk in February 2017 by authors ADV and KEK (De Vries and Kaylegian, 2017). The team had experience in dairy management and processing. A local dairy expert from Heifer International Nepal arranged all visits to farms, MCC, processing centers, government institutions, and universities, and served as an interpreter during these visits. The sites were located in Kathmandu and Chitwan, areas with concentrated dairy production and processing. The climate around Kathmandu is mild, and generally warm and temperate, typically with highs in the 20 to $24^{\circ} \mathrm{C}\left(68\right.$ to $\left.75^{\circ} \mathrm{F}\right)$ and lows in the 5 to $8^{\circ} \mathrm{C}\left(41\right.$ to $\left.46^{\circ} \mathrm{F}\right)$ range. The summers are much wetter than the winters. Chitwan is located in the subtropical central climatic zone of the Himalayas, with monsoons in the summer. The sites chosen represented 
a range of facility sizes and operational practices. The team had the opportunity to meet with farmers, processing plant personnel, and dairy officials, to tour the facilities, and to observe daily activities and practices. The visits to each farm or facility typically lasted 1 to $3 \mathrm{~h}$. The goal of the rapid needs assessment was to get a holistic view of the challenges and opportunities for training in the Nepal dairy sector and supplement the information from the literature review (Appendix 2).

Dairy Management. Dairy cattle that are no longer productive are a problem for dairy farmers because they legally cannot be slaughtered in this predominantly Hindu country. This includes young male calves. These cattle are often not well cared for (to reduce costs) or are allowed into public spaces. In contrast, buffalo can be slaughtered. The use of sexed semen would diminish the problem of male calves but could create a surplus of dairy heifers. However, we received mixed messages about the need for more heifers. Feed availability limits the number of cows that farmers can keep. Infertility was also reported to be a major problem but the number of inseminations per conception (3) was not exceptionally high. Farmers did not show records to support their claims.

The genetic merit of the current population of dairy cattle was lower than that available in the United States. Most dairy cattle were of Holstein-Friesian or Jersey origin from semen or cows imported decades ago. As a general practice in Nepal, farms are associated with a single veterinary technician who also does the artificial breeding and uses the same bull on all of a farm's heifers and cows for $1.5 \mathrm{yr}$, after which time the bull is replaced. This practice leads to a high risk of low genetic progress if the bull is of low genetic merit, as is often the case.

Mastitis is considered a real problem by dairy farmers. The fact that mastitis reduces milk production and fertility was not well understood. We noted a limited understanding about the need to maintain a withdrawal period (milk not to be sold) for drug residues after treatment of cows with antibiotics.

We noticed that cow comfort is often limited. Tie stalls are used and cattle are on concrete bedding. Heat stress abatement is generally not available, even in subtropical Chitwan. Limited water availability to cattle is a missed opportunity we observed on several farms. Farmers did not limit access to water sources was not limited but they lacked knowledge about the quantity of water that cattle need. Many cattle do not have access to water all the time.

Many stakeholders identified forage quality and availability as a problem. Forage growth is seasonal, so no fresh forage is available during the dry (winter) season, only hay. Silage was not regularly made but many stakeholders mentioned silage as an option to invest in. Others said, however, that silage making had been tried in the past but was not adopted by farmers. An economical silage-making method or program could have a major impact on dairy production in Nepal.

The price of concentrate (wheat bran-based) was said to be very high compared with the price of wheat and the price of milk. The farmers told us that the high concentrate price is a political decision they could not affect. Often only one feed concentrate option is available from the farmers' cooperative. Different feed concentrates are needed for a balanced ration during the year because the availability and quality of forages is seasonal. The formulation of the available concentrate does not change during the year, however. It would be helpful for dairy advisors to have access to ration formulation tools to ensure improved balanced feed rations. Feedstuffs also need to be analyzed for nutritional composition so shortages in the composition may be addressed. An app for cell phones has recently been developed to aid ration formulation in Nepal, with good results (LSIL, 2019).

\section{Milk Collection and Processing}

Five of the sites visited were collection centers, processing plants, or both. Three sites were rural collection centers and one of these centers had its own processing plant for milk, ghee, and curd (yogurt). One site was a rural processing plant that made milk, ghee, and curd, and one site was a large urban processing plant that made milk, condensed milk, and ice cream.

MCC. Milk is received at rural collection centers and processing plants in plastic or metal cans and is typically transported unrefrigerated on bicycle, motor bike, or carried by hand from the farms. The milk is stored at the MCC in refrigerated holding tanks until it is processed or picked up for further delivery. The urban plant receives milk in a refrigerated tanker truck that is obtained from the rural MCC. Tanker trucks are washed at the processing plant after unloading. The milk cans are sometimes rinsed and less often washed with soap at the MCC.

Milk is occasionally tested for solids or fat at the MCC as a basis for farmer payment, and the equipment is not routinely calibrated. There is no testing for quality indicators such as microbial count and SCC or even an odor test. For social reasons, milk is rarely rejected, however; therefore, there is no price incentive for farmers to improve milk quality.

Several issues were identified at the MCC that may contribute to reduced quality of the raw milk and reduced quality and shelf life of the finished products. These are the lack of a cold chain from the farm, lack 
of good sanitation practices for the milk cans, and potential deterioration of the milk fat during transport over rough roads. The lack of cold chain and routine cleaning of milk cans may lead to increased growth of spoilage organisms with enzymes that cause flavor issues and deteriorate fat and protein. The potential for turbulence during transport may cause breakdown of fat globules, resulting in rancid flavors.

Processing Plants. There were notable differences between the small rural and the large urban processing plants. The rural plants had equipment and facilities that were older and in need of repairs, whereas the urban plant was more modern. One of the rural plants used an HTST pasteurizer and the other used a vat pasteurizer. Neither processor routinely calibrated the thermometers used to record pasteurization temperature. Cleaning in the first facility was done manually with caustic because the clean-in-place (CIP) system was broken and the employees noted that the equipment design made it difficult to clean thoroughly. The second facility rinsed the equipment with hot water daily but only cleaned with caustic every other day. Neither facility used acid cleaners to remove milk mineral residues, nor did they have any type of sanitizing processes (hot water or chemical) that they used before processing.

If the processing plants conducted testing on the incoming milk, it was for fat content or a clot-on-boil test to check for acidity. Milk with a high fat content is considered to be of higher quality because the processor can use the fat to make ghee and still have a reasonable yield for their curd or milk processing. The shelf life of pasteurized milk was typically only 2 to $3 \mathrm{~d}$. It was indicated that this because of the lower quality of the incoming raw milk, inability to clean equipment thoroughly, and postpasteurization contamination. The lack of sanitizing before processing also contributes to this problem. Milk is typically boiled by the consumer before consumption, so spoilage seemed to be of higher concern than presence of pathogens.

Management in all 3 processing plants expressed a need for more training in good manufacturing practices (GMP) among all employees, as well as cleaning and sanitizing practices for equipment. The processors we visited had soap and towels available in the toilet rooms to encourage GMP but they were not always used by workers.

\section{General Observations}

Most of the stakeholders in Nepal were keenly aware of the major problems and opportunities facing the dairy industry in Nepal. However, they were likely not aware about the detailed principles, techniques, and methods to solve some of these problems, such as practicing good hygiene. We were often told that "farmers simply don't know." Lack of training and lack of access to training materials contribute to the problem. Further, few (financial or cultural) incentives exist to change practices. It is not clear how knowledge transfer is sustainable without incentives to change practices.

To the many stakeholders in Nepal, milk "quality" means fat and solids-not-fat. It does not mean measures such as aroma, SCC, bacterial count, or shelf life, which are commonly associated with milk quality in the United States. In this paper, we use the definition of milk quality common in the United States. These different definitions hindered communication about milk "quality" with stakeholders in Nepal. Milk quality in terms of SCC or bacterial level is generally not measured and not known in Nepal. The short shelf life of pasteurized milk is considered a major problem.

Sanitation was an issue throughout the production and processing continuum. We saw water and soap at some farms but also a milker moving manure out of the way with his hand. There seemed to be little awareness of the importance of personal hygiene around milking. We were told that knowledge regarding sanitation of milk equipment was lacking. Demonstrations on proper ways to clean hands, cows, and equipment for milking and processing would be useful but need to include good information on why cleaning is important and why it should be done consistently. The use of regular cleaning with detergents (caustic) and daily sanitizing in processing plants will improve the quality and shelf life of dairy products.

We heard from many stakeholders that seeing something in person is the preferred method of learning. Classroom lectures do not work well. Farmers and their trainers need access to improved farms (model farms) that use production practices that are within reach of the common dairy farmer. Such farms should be the same size (small) and use the same resources as local farms. We often heard that there is a need for practical hands-on training in dairy management and processing. This includes seeing and working with good practices.

Recommendations from the Rapid Needs Assessment. We make the following recommendations for further steps. (1) Engage with stakeholders in Nepal to develop projects that are specific, measurable, attainable, relevant, and timely. These projects need to focus on capacity building of institutions working with dairy farmers and processors within Nepal. (2) Address the high price of feed ingredients to improve dairy cattle rations. Cheaper and more widely available feed ingredients will boost milk production. This effort should include use of rapid nutrient analysis equipment (e.g., near infrared) so that the major concerns on 
the quality of feeding resources can be addressed in a reasonably short time with appropriate and affordable supplements. (3) Provide incentives for dairy farmers, milk chilling centers, and MCC to supply milk with higher quality. Such incentives could be monetary or cultural, such as awards, prestige, rankings, and so on. (4) Develop a training program for training of trainers on practical dairy management such as availability of water, cow comfort, mastitis control, and personal and cattle hygiene. (5) Support establishment of model dairy farms in dairy pockets of the country. These may be modifications of existing farms where adoptable and simple technologies can be demonstrated such as making water available $24 \mathrm{~h} / \mathrm{d}$, plastic bag or barrel silage techniques, adoption of good hygiene practices, and others. (6) Pilot good hygiene practice (GHP) and GMP implementations at MCC and chilling centers and implement training of trainers, milk handlers, and farmers on GHP/GMP. (7) Conduct economic analyses of dairy farming, including identifying areas to reduce the cost of milk production and recommend appropriate farm sizes for different settings (e.g., availability of resources, markets). (8) Implement simple milk quality measurement systems at various MCC. Measure bacteria, SCC, or other measures of quality that affect shelf life (e.g., technology used in Rwanda projects by LSIL). Implement competitions within MCC for milk quality, with rewards that are nonfinancial (e.g., blue ribbons, awards, rankings, photos in newspaper) and eventually financial (zero-sum penalty/price structure within the MCC). Document the level of milk quality over time and the impact of training or a bonus system. Survey winning farms to learn about their management practices. (9) Organize internships in the United States for local trainers and assist with curriculum development for dairy science students in Nepal.

The next steps should include outreach to stakeholders in Nepal to make concrete project proposals, develop training materials and training curricula for training-of-trainers workshops, and explore funding possibilities for the potential projects. The training of farmers on the aspects of milk that cause quality issues and cleaning of milk cans was a reasonable option for developing training modules. Basic training in GMP and sanitation practices was determined to be the best focus of future training modules.

\section{Training of Trainers in Nepal}

Training Program Design. Based on the rapid needs assessment, we determined that we would have the most impact by training the milk processors, even though milk quality issues originated at the farm level.
A training program was developed based on the oneday Penn State Dairy Basics: Fundamentals of Quality and Safety workshop. It was converted to a training-oftrainers approach and modified for the Nepal stakeholders with appropriate pictures and scenarios gathered during the needs assessment. The course was expanded to a 2-d curriculum to cover all the topics needed, provide time for practical sessions and questions and answers, and for translation during the program. The training-of-trainers manual and slides were written in English and translated to Nepali before the trainings.

The course had 3 main modules: the basics of milk and dairy food processing, GMP, and cleaning and sanitizing in a dairy plant. The course learning objectives were (1) to recognize the different factors and best handling practices that contribute to high quality and safe dairy foods; (2) to identify unclean areas found in a dairy processing plant and be able to apply best practices for cleaning and sanitizing equipment, facilities, and personnel as appropriate; and (3) to identify hazards in a dairy processing environmental and describe how to control them.

The course consisted of 10 lectures, including one on how to use the curriculum in different ways so that the trainers could complete smaller modules to meet the needs of the specific stakeholders and time available. There were 4 practical activities in the course: handwashing demonstration with Glo Germ (Glo Germ Company, Moab, UT), equipment washing demonstration with Glo Germ, GMP walk-though inspection in the processing plant, and a sanitation standard operating procedure writing exercise in the classroom. The course was intended to be held in or near a processing plant to facilitate the practical sessions on equipment washing and GMP inspections (Appendix 3).

The course materials for each trainer consisted of a printed binder with all the lectures slides and transcripts, as well as suggestions for adding personal stories and examples throughout the course. A USB flash drive was provided with the Microsoft Word documents and PowerPoint slides in both languages. Additional resources included on the USB flash drive were the US regulations for current GMP, hazard analysis, riskbased assessment, and preventive controls for human food (21CFR117), the Pasteurized Milk Ordinance (FDA, 2015), and food safety posters and tip sheets from Penn State Extension.

A supplemental training kit was provided for sharing, because there was no funding to provide one for each trainer. The kit included flipchart post-it notes and markers; soap, paper towel, and a Glo Germ kit for hand washing and equipment washing demonstrations; clipboard, pen, and flashlight for GMP inspec- 
tions; Penn State Extension food safety and sanitation posters; and Dairy Practices Council dairy quality and sanitation guidelines.

Author KEK and a graduate student conducted the training program in Chitwan and Kathmandu in August 2018. There were 19 male participants in Chitwan and 24 participants (17 male and 7 female) in Kathmandu. All trainers were from the dairy industry, had technical backgrounds, and spoke English. The program was given in English, using dual slide projectors for the English and Nepali versions of the slides, and the translator was present at all times to clarify concepts, answer questions, and facilitate discussions. A full description is given in Kaylegian (2018).

Results of Trainings and Impacts. The 2-d timeframe for the complete course was adequate to cover the lecture material, activities, and discussions. However, due to circumstances beyond our control, the trainings were not held at dairy processing plants so arrangements were made for each training group to visit a local processing plant to conduct the GMP inspection activity. The agenda was rearranged as needed at each site to accommodate transportation to the dairy processing plants, and this served as a discussion point on how the trainers can modify the course modules and activities to meet future situations. The practical equipment washing demonstration with Glo Germ was omitted because of the location change, but the demonstration was described so that the trainers were comfortable conducting this activity in their own trainings.

All lecture materials and activities were well received and participants were able to make the connections between the delicate nature of milk, factors affecting quality, and best practices from farm to processor to consumer. The participants at both locations were quite engaged and asked questions throughout the course. The handwashing demonstration was successful and Glo Germ was an excellent visual tool for people to see how to properly wash their hands to remove dirt and microorganisms. Using an activity like this is important when teaching skills and it gives people an opportunity to do and see and integrate, rather than just listen and absorb. The group was large during the plant walk-through GMP inspection and it was difficult to keep everyone's attention during the process. Again, this type of activity is quite valuable in getting out of the classroom to see real-world examples of things that are wrong and provide real-time feedback on how to fix them. For future trainings, it is recommended that this activity is done in groups of 10 people or fewer to facilitate learning.

The feedback from participants was very positive throughout the course. Several senior managers in the course commented that the material was on target for what they needed. Most of the participants thanked us individually after the course for sharing our time and knowledge. Some comments we received included "We learned more than we expected to" and "We have not seen information before on how to write standard operating procedures and sanitation standard operating procedures and these will be very helpful."

Due to lack of funding and personnel, a 6-mo followup was not planned or executed. A casual check with Nepal contacts a year later indicated that although the training we provided was helpful, there was no funding for the trainers to conduct additional trainings for other dairy stakeholders and not much was being done until funding could be procured in the future.

\section{DISCUSSION AND CONCLUSIONS}

Our goals were to document the status of the dairy farming and milk processing in Rwanda and Nepal and to identify gaps in knowledge and opportunities for education through training-of-trainers programs. The unstructured literature reviews provided some initial background information, but little reliable data in English were found. Most of the literature was provided by LSIL partners in Rwanda and Nepal, who were very familiar with the local dairy industries.

The rapid needs assessments provided necessary insights into the dairy sectors in Rwanda and Nepal. We necessarily focused on areas that had challenges, but we were impressed by the ability of local stakeholders to make the best of the available resources and knowledge. Both countries have mostly smallholder dairy herds with lower genetic merit and lower productivity compared with cows in US herds. This is primarily due to poorer forage quality and lack of concentrates and to health problems such as mastitis. Combined with suboptimal hygiene and challenged with milk cooling, this resulted in milk with lower quality being delivered to MCC and eventually to processors. Lack of proper cleaning through all phases at milk processors contributed to poorer milk quality and short shelf life. Local dairy stakeholders broadly identified the same issues that the literature and our direct observations provided.

The approach of conducting a rapid needs assessment of the dairy production chain to determine opportunities for training was a solid idea. Many issues that affect milk quality and safety start on the farm and may be overlooked when on-farm dairy production and dairy processing are considered separately. The dairy production chain is a continuum that relies on both parts of the industry for each to be successful. The more that can be done to integrate production and processing collaboration, the better the industry will fare in all countries. 
There were positive and negative aspects of doing a "rapid" needs assessment that affected training for the processors. It was good to see the production side of the industry to put the processor training in perspective, and to be able to support the need for basic sanitation for dairy milkers and at the collection centers. A limitation was that not enough time was allocated to thoroughly assess the situations at the processing plans to optimize the processor training.

There were clearly limitations on what could be learned from our literature reviews and rapid needs assessments. One limitation was the quality and quantity of literature available to us in English. Another limitation was that only 1 wk was allotted to visit many sites in each country, so each visit was short. The local organizers necessarily had to choose which sites were available for the rapid needs assessments. In Nepal, we relied on translators to interact with stakeholders. Customs and beliefs regarding dairy cattle management and milk processing in both countries were quite different from our experiences and we may have missed important clues. Taken together, these factors place some limitations on the results and conclusions regarding improvement of productivity, quality, and safety of milk in Rwanda and Nepal in this study.

We learned only at the end of the rapid needs assessment that the term "milk quality" meant different things to us and to Rwandan and Nepali stakeholders. The investigators from the United States considered high-quality milk to have low microbial and somatic cell counts and no obvious off-odors or visible deterioration, whereas the Nepali and Rwandan stakeholders viewed high-quality milk as having a high fat content so that they could process more ghee and curd from the same batch of milk. A key finding from this needs assessment is to clarify terms and talking points to make sure everyone involved at all stages is using the same terminology.

References were made during the cleaning and sanitizing lectures to work with the chemical supplier to determine the correct chemicals and concentrations to use. We learned that there are no "chemical suppliers" in Nepal similar to those in the United States. Often chemicals are delivered in bulk with no information on concentration and usage rates, and processors do not routinely check concentration before use. A module on chemical usage rates and checking concentration would be very valuable to ensure that equipment is properly cleaned and to reduce the risk of postpasteurization contamination, which leads to short shelf life and poor quality products.

One of the participants noted that microbial counts are good in their ice cream product sampled before packaging but not after packaging, and asked how they could sanitize packaging materials because they thought the packaging material was contaminated when it came from the manufacturer. The packaging materials were not the issue, but the problem was that people were not trained on how to handle the packaging in a sanitary manner. Packaging was stored directly on wet floors and filled by picking up with fingers inside the containers, thus contaminating the package. These GMP could have been addressed specifically during training by using photographs, had we been aware of them during the needs assessment. After this discussion, these practices in the plant were changed the next day.

The overall impressions of the processor trainings were that the materials and activities were on target and valuable to the Nepal dairy stakeholders. The core of the training program Dairy Basics: Fundamentals of Quality and Safety is the in-person course at Penn State University, which is designed to be flexible for different audiences with the changing of photographs and examples. The conversion to a training-of-trainers format is one that can also be adapted for use in other countries. A key recommendation before using this or other curricula in different countries is to schedule adequate time to visit with local processors to learn their practices and concerns, take a few days to integrate this information, and then revisit these locations to collect photographs, videos, and examples during the needs assessment. This approach will provide the material that can be incorporated into the training curricula to better meet the needs of specific areas and situations. Trainings such as these are most effective when the participants see situations, people, and equipment that are familiar to them and that they can relate to. Showing ideal situations that are not attainable will not have the same long-lasting changes in behavior and impact on improving dairy quality and safety.

A similar training-of-trainers approach was used for smallholder dairy systems in Malawi with great success (Kazanga, 2012). The program in Malawi focused on training on mastitis prevalence and milk yield, barn cleanliness, milk rejection at MCC, utensil hygiene including personal hygiene, and water and feed availability for cows. As a result of the training, production of human-consumable milk delivered to MCC increased by more than $25 \%$. This increase was due to training alone and was not connected to improved access to feed supplements, which would be expected to enhance this response (Kazanga, 2012).

Those who deliver training-of-trainers program must understand the conditions in these developing dairy countries well, but this takes time. None of the 3 authors have long-term commitments to dairy stakeholders in Rwanda or Nepal. Long-term sustained efforts are needed to improve the productivity, quality, and 
safety of milk in Rwanda and Nepal. There are many barriers to change that take time to understand but will affect the success of training-of-trainer efforts. Lack of funding hampered further implementation of trainingof-trainers programs. However, several grant-funded programs by LSIL aligned with the findings from the rapid needs assessments are underway.

In conclusion, Rwanda and Nepal both have smallholder dairy farms that often face similar challenges such as lack of quality feeds, needs for basic dairy management education, low cattle productivity, and poor milk quality. Training-of-trainers programs to address these basic issues may be successful, but limited funding hampers sustained implementation, and follow-up studies to evaluate their long-term effectiveness are needed.

\section{ACKNOWLEDGMENTS}

This work was funded in whole or part by the United States Agency for International Development (USAID) Bureau for Food Security under Agreement \# AIDOAA-L-15-00003 as part of Feed the Future Innovation Lab for Livestock Systems. Any opinions, findings, conclusions, or recommendations expressed here are those of the authors alone. Anil Sigdel (University of Florida, Gainesville, FL) helped to prepare the background information on the dairy sector in Nepal. The authors thank the many local stakeholders who participated in both rapid needs assessments. Special thanks go to the local hosts, Bhola Shankar Shrestha from Heifer International Nepal, Jean Baptiste Ndahetuye from the University of Rwanda, and Felix Ngamije in Rwanda. The authors have not stated any conflicts of interest.

\section{REFERENCES}

Adesogan, A. T., A. H. Havelaar, S. L. McKune, M. Eilittä, and G. E. Dahl. 2019. Animal source foods: Sustainability problem or malnutrition and sustainability solution? Perspective matters. Glob. Food Secur. 100325. https://doi.org/10.1016/j.gfs.2019.100325.

Adhikari, B. M., R. P. Subedi, and D. Subha. 2012. A study on standard of buffalo meat hygiene in Dharan. J. Food Sci. Technol. 7:98-101.

Arjyal, C., B. N. Dahal, and B. Khadka. 2004. Microbial quality of milk available in Kathmandu valley. J. Nepal Med. Assoc. 43:137140. https://doi.org/10.31729/jnma.475.

Bishop, H., and D. Pfeiffer. 2008. Factors effecting reproductive performance in Rwandan cattle. Trop. Anim. Health Prod. 40:181184. https://doi.org/10.1007/s11250-007-9078-1.

CBS (Central Bureau of Statistics). 2013. National Sample Census of Agriculture Nepal 2011/12. National Report, Government of Nepal, National Planning Commission Secretariat, Central Bureau of Statistics, Kathmandu, Nepal, December 2013. http://www .fao.org/fileadmin/templates/ess/ess_test_folder/World_Census _Agriculture/Country_info_2010/Reports/Reports_5/NPL_EN _REP_2011-12.pdf.

Dahl, G. E., and S. Hendrickx. 2018. Rapid Assessment of the Gaps in Dairy Cattle Feeding and Management that Constrain Milk Qual- ity and Quantity in Rwanda. Feed the Future Innovation Lab for Livestock Systems, Gainesville, FL.

De Vries, A., and K. E. Kaylegian. 2017. Rapid Assessment of the Gaps in Dairy Cattle Feeding, Management and Milk Processing That Constrain Milk Quality and Quantity in Nepal. Feed the Future Innovation Lab for Livestock Systems, Gainesville, FL.

Dhakal, I. P., P. Dhakal, T. Koshihara, and H. Nagahata. 2007. Epidemiological and bacteriological survey of buffalo mastitis in Nepal. J. Vet. Med. Sci. 69:1241-1245. https://doi.org/10.1292/jvms.69 .1241.

Ezeanya, C. 2014. Indigenous knowledge, economic empowerment and entrepreneurship in Rwanda: The Girinka approach. J. Pan Afr. Stud. 6:241-263. Accessed Feb. 1, 2020. http://www.jpanafrican .org/docs/vol6no10/6.10-19-Ezeanya.pdf.

FDA (United States Food and Drug Administration). 2015. Grade "A" Pasteurized Milk Ordinance. U.S. Dept. of Health and Human Services, Public Health Service, Food and Drug Administration. Washington, DC.

FAO (Food and Agriculture Organization of the United Nations). 2010. Dairy Sector Study of Nepal. Accessed Feb. 1, 2020. http:// nepalagritech.com.np/wp-content/uploads/2016/10/Dairy-Sector -in-Nepal-FAO.pdf.

IFAD (International Fund for Agricultural Development). 2016. Rwanda Dairy Development Project: Detailed design report. Republic of Rwanda. Report No: 4167-RW. https://operations.ifad.org/ documents/654016/dac88c28-8e89-48c8-8357-51eea2f017fb.

Kamanzi, M., and C. Mapiye. 2012. Feed inventory and smallholder farmers' perceived causes of feed shortage for dairy cattle in Gisagara District, Rwanda. Trop. Anim. Health Prod. 44:1459-1468. https://doi.org/10.1007/s11250-012-0087-3.

Kaylegian, K. E. 2018. Report on Train-The-Trainer Dairy Food Basics: Fundamentals of Quality and Safety. Feed the Future Innovation Lab for Livestock Systems, Gainesville, FL.

Kazanga, D. T. 2012. The impact of dairy management training of small-scale dairy farmers on milk yield and quality in Malawi. MSc Thesis. University of Florida, Gainesville. Accessed April 1, 2020. https://ufdc.ufl.edu/UFE0045131/00001.

Klapwijk, C. J., C. Bucagu, M. T. van Wijk, H. M. J. Udo, B. Vanlauwe, E. Munyanziza, and K. E. Giller. 2014. The 'One cow per poor family' programme: Current and potential fodder availability within smallholder farming systems in southwest Rwanda. Agric. Syst. 131:11-22. https://doi.org/10.1016/j.agsy.2014.07.005.

Land O'Lakes. 2016. Milk plays a dramatic role. Accessed Feb. 1, 2020. https://www.landolakes.org/resources/success-stories/milk -plays-a-dramatic-role.

LSIL. 2019. Innovation summary: Mobile app-based feeding support tool to optimize dairy animal productivity. Feed the Future Innovation Lab for Livestock Systems. Accessed April 1, 2020. https: / /ivestocklab.ifas.ufl.edu/media/livestocklabifasufledu/pdf-/ Shrestha_Heifer_NEPAL_Innovation-Summaries_April-2019.pdf.

Maharjan, M., V. Joshi, D. D. Joshi, and P. Manandhar. 2006. Prevalence of Salmonella species in various raw meat samples of a local market in Kathmandu. Ann. N. Y. Acad. Sci. 1081:249-256. https: //doi.org/10.1196/annals.1373.031.

McMahon, K. 2016. Herding livestock programs toward nutrition: a critical analysis with a focus on Rwanda's Feed the Future dairy program. Center for Strategic and International Studies. Accessed Feb. 1, 2020. https://csis-prod.s3.amazonaws.com/s3fs-public/ publication/161122_McMahon_HerdingLivestock_Web.pdf.

MINAGRI (Ministry of Agriculture and Animal Resources). 2013. National Dairy Strategy 2013. Government of Rwanda, Kigali, Rwanda.

MoAD (Ministry of Agricultural Development). 2012. Statistical Information on Nepalese Agriculture. Agribusiness Promotion and Statistics Division, Agric. Statistics Section, Singhdurbar, Kathmandu Nepal.

MoLD (Ministry of Livestock Development). 2016. Commitment paper (in Nepali). Accessed Feb. 1, 2020. http://www.mold.gov.np/ uploads/files/pratibaddata.pdf. 
NARC (National Agricultural Research Council). 2016. Animal Breeding Division. Accessed Feb. 1, 2020. http://narc.gov.np/animal -breeding-division/.

Ndahetuye, J. B. 2019. Mastitis in dairy cows in Rwanda: Prevalence, aetiology, antimicrobial resistance, molecular epidemiology and effects on milk qual. PhD. Diss. Swedish Agricultural University, Uppsala. Accessed April 1, 2020. https://pub.epsilon.slu.se/ 16465/7/ndahetuye_jb_191127.pdf.

Ndahetuye, J. B., Y. Persson, A.-K. Nyman, M. Tukei, M. P. Ongol, and R. Båge. 2019. Aetiology and prevalence of subclinical mastitis in dairy herds in peri-urban areas of Kigali in Rwanda. Trop. Anim. Health Prod. 51:2037-2044. https://doi.org/10.1007/ s11250-019-01905-2.

Pande, R. S. 1997. Fodder and pasture development in Nepal. Udaya Research and Development Services (P) Ltd. Kathmandu, Nepal.

Samarth-Nepal. 2016. Reducing poverty by making rural markets work for the poor. http://samarth-nepal.com/portfolio/dairy/.

Sharma, B., and K. Banskota. 2002. Smallholder dairy farming in Nepal: Characteristics, constraints, and development opportunities. Chapter 5 in Smallholder Dairy in Mixed Farming Systems of the HKH. Pradeep Man Tulachan, Mohammad A. Jabbar, M. A. Mohamed Saleem. A. Beatrice Murra, ed. The International Centre for Integrated Mountain Development, Lalitpur, Nepal.

Shrestha, S., and Y. R. Bindari. 2012. Prevalence of sub clinical mastitis among dairy cattle in Bhaktapur district Nepal. Int. J. Agric. Biosci. 1:16-19.
SYB. 2015. Rwanda Statistical Yearbook 2015. Republic of Rwanda, National Institute of Statistics of Rwanda, Kigali.

Upadhaya, M., N. Poosaran, and R. Fries. 2012. Prevalence and predictors of Salmonella spp. in retail meat shops in Kathmandu. J. Agric. Sci. Technol. 2:1094.

Upreti, C. R. and B. K. Shrestha. 2006. Nutrient Contents of Feeds and Fodder in Nepal. 1st ed. Animal Nutrition Division, NARC, Khumaltar, Nepal.

World Food Programme. 2016. Rwanda 2015: Comprehensive food security and vulnerability analysis 2015. Accessed Feb. 1, 2020 https://documents.wfp.org/stellent/groups/public/documents/ ena/wfp284395.pdf

World Health Organization. 2014. World health assembly global nutrition targets 2025: Stunting policy brief. Accessed April 1, 2020. http://www.who.int/nutrition/topics/globaltargets_stunting _policybrief.pdf.

\section{ORCIDS}

A. De Vries (ํ) https://orcid.org/0000-0003-4511-0388

K. E. Kaylegian ๑ https://orcid.org/0000-0003-2835-3089

G. E. Dahl ๑ https://orcid.org/0000-0002-2182-6317

\section{APPENDIX 1}
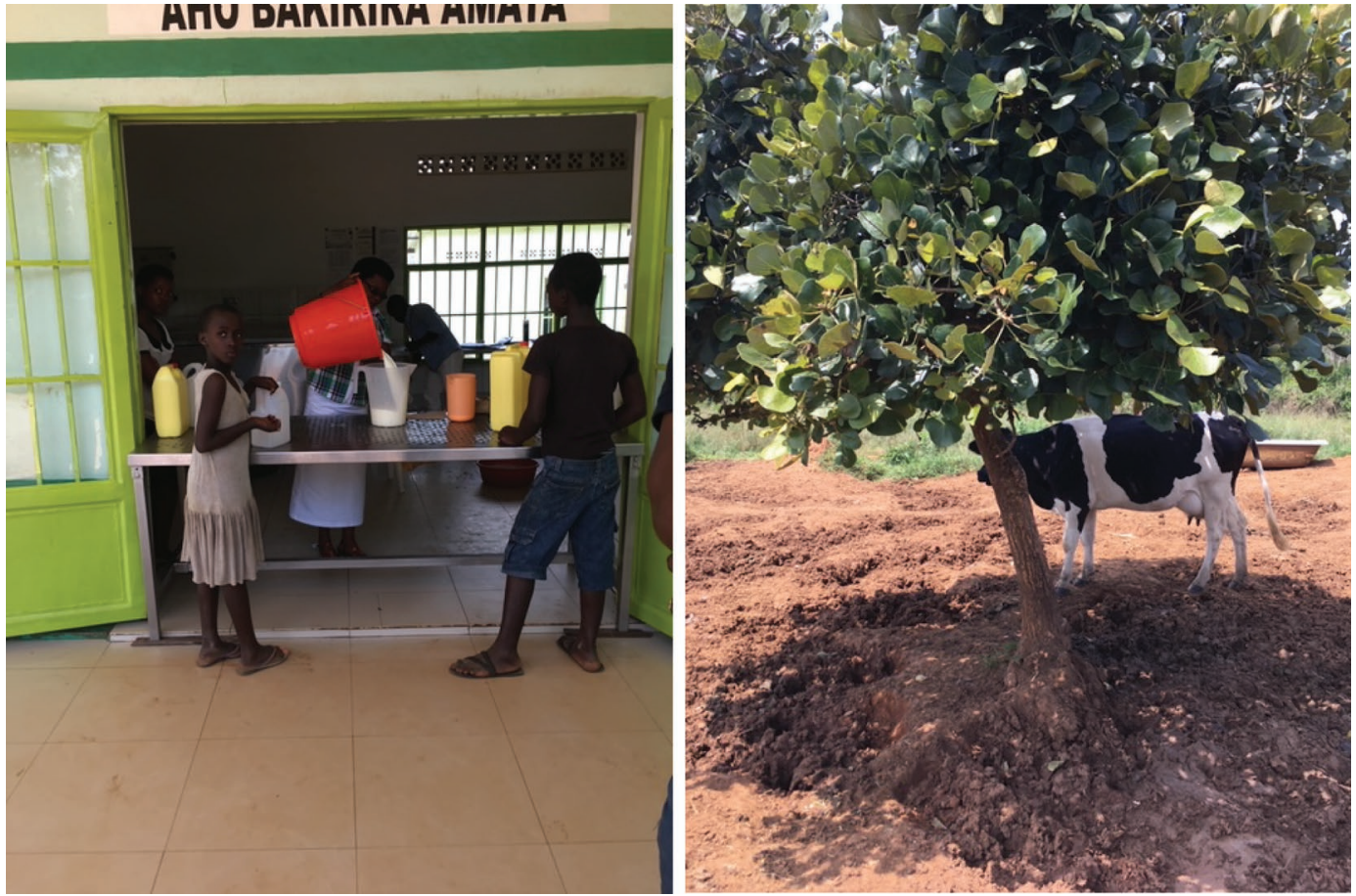

Figure A1. Typical milk cooling center in Rwanda where milk is brought by local farmers, cooled, and then sold to consumers (left). Typical outdoor housing for cows in Rwanda; shade is limited (right). Photographs taken during the rapid needs assessment in Rwanda (courtesy of G. E. Dahl). 


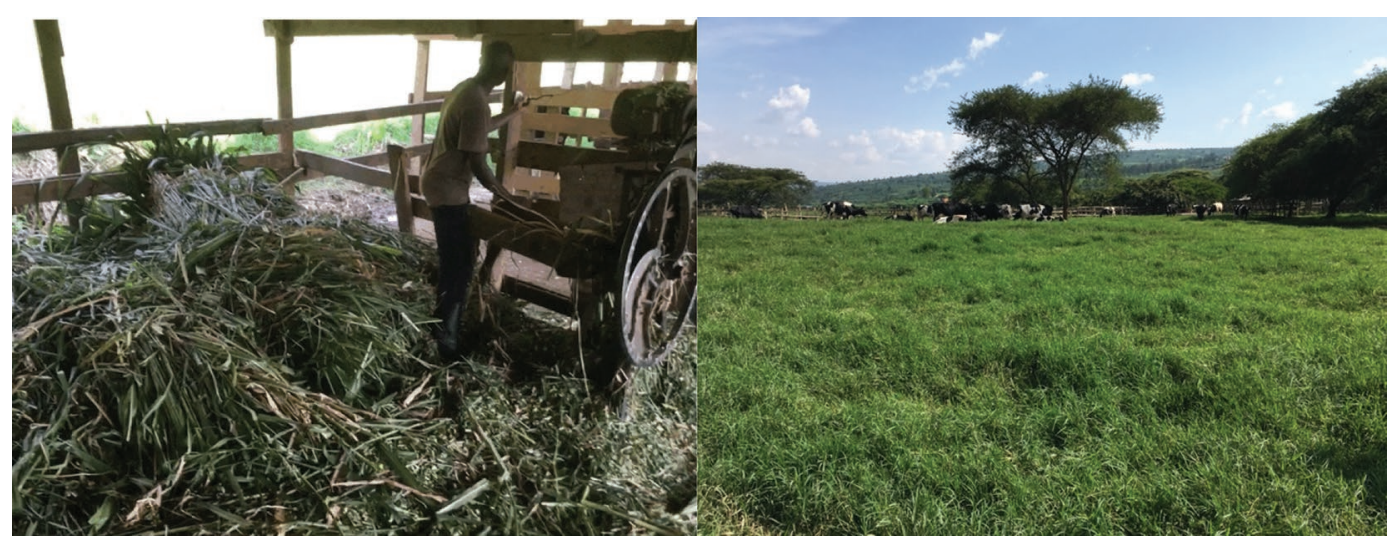

Figure A2. Napier grass is a common forage fed to cattle in Rwanda. It is harvested fresh each day and chopped (left). Cattle on pasture on a farm near Kigali, Rwanda (right). Photographs taken during the rapid needs assessment in Rwanda (courtesy of G. E. Dahl).

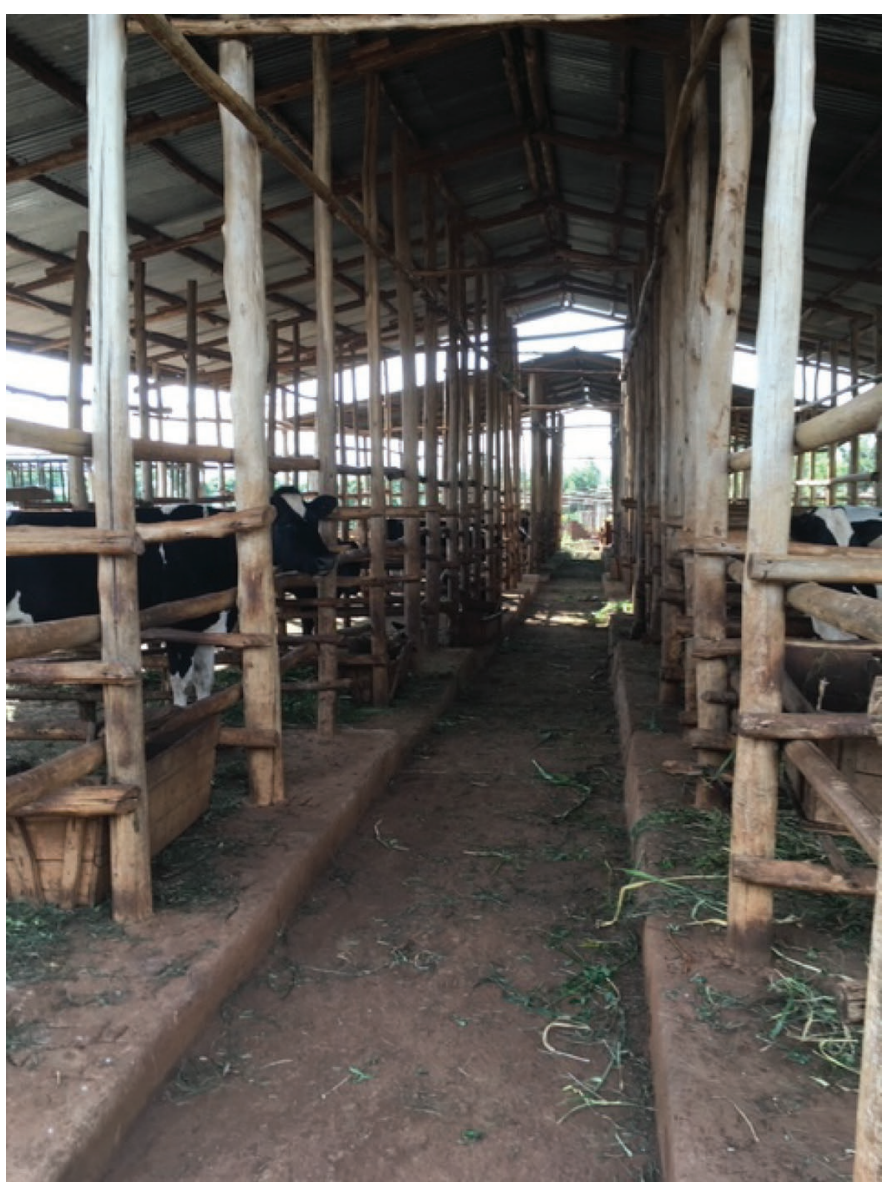

Figure A3. A "kraal" or communal housing for cows owned by individuals in the Girinka program in Rwanda. Photographs taken during the rapid needs assessment in Rwanda (courtesy of G. E. Dahl). 


\section{APPENDIX 2}
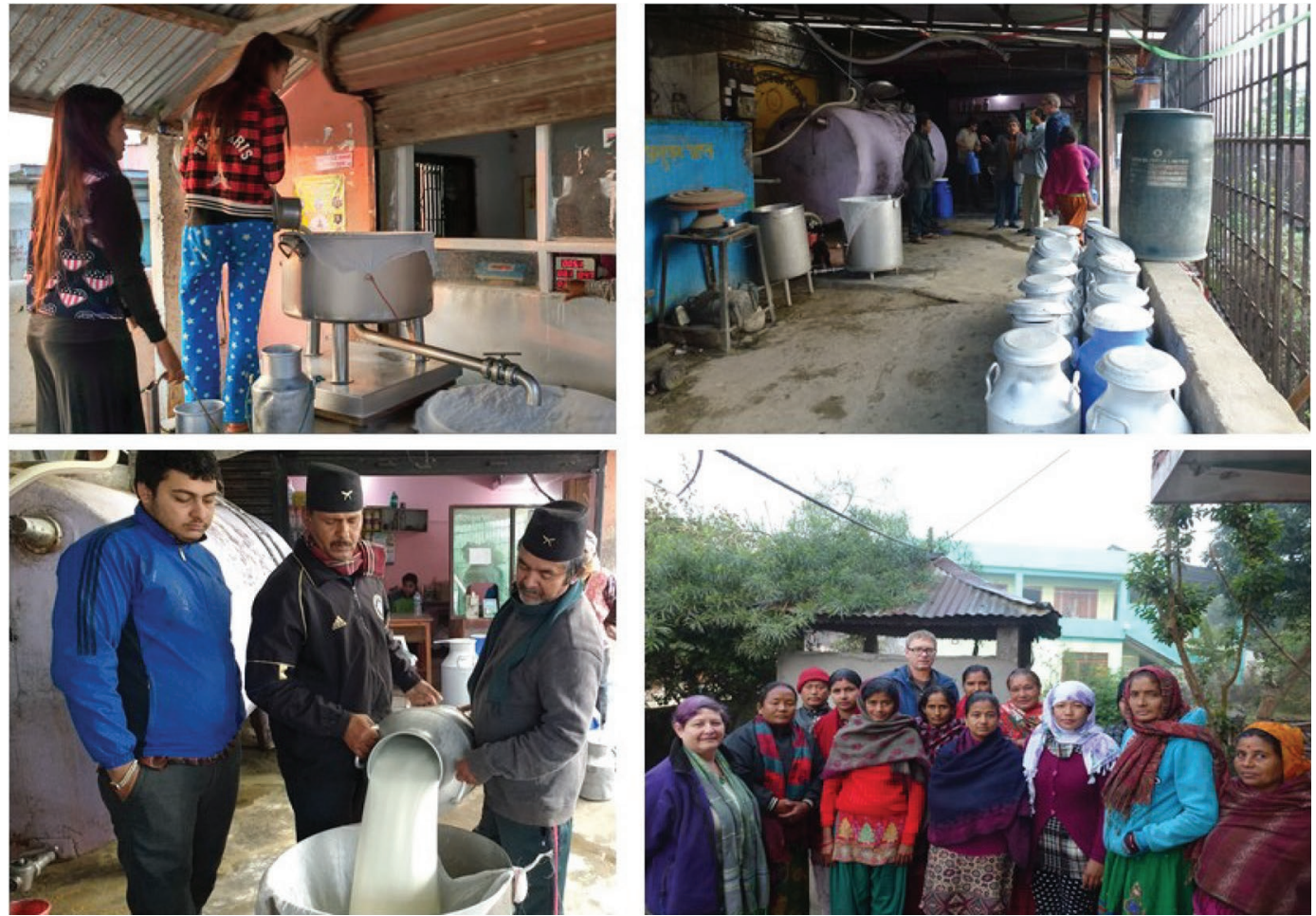

Figure A4. Women delivering milk to a milk collection center near Chitwan, Nepal (top left). Bulk can storage of milk at a milk collection center near Chitwan, Nepal (top right). Men delivering milk to a milk collection center near Chitwan, Nepal (bottom left). Women farmers cooperative in Devghat, Nepal (bottom right). Photographs taken during the rapid needs assessment in Nepal (courtesy of K. E. Kaylegian and A. De Vries).
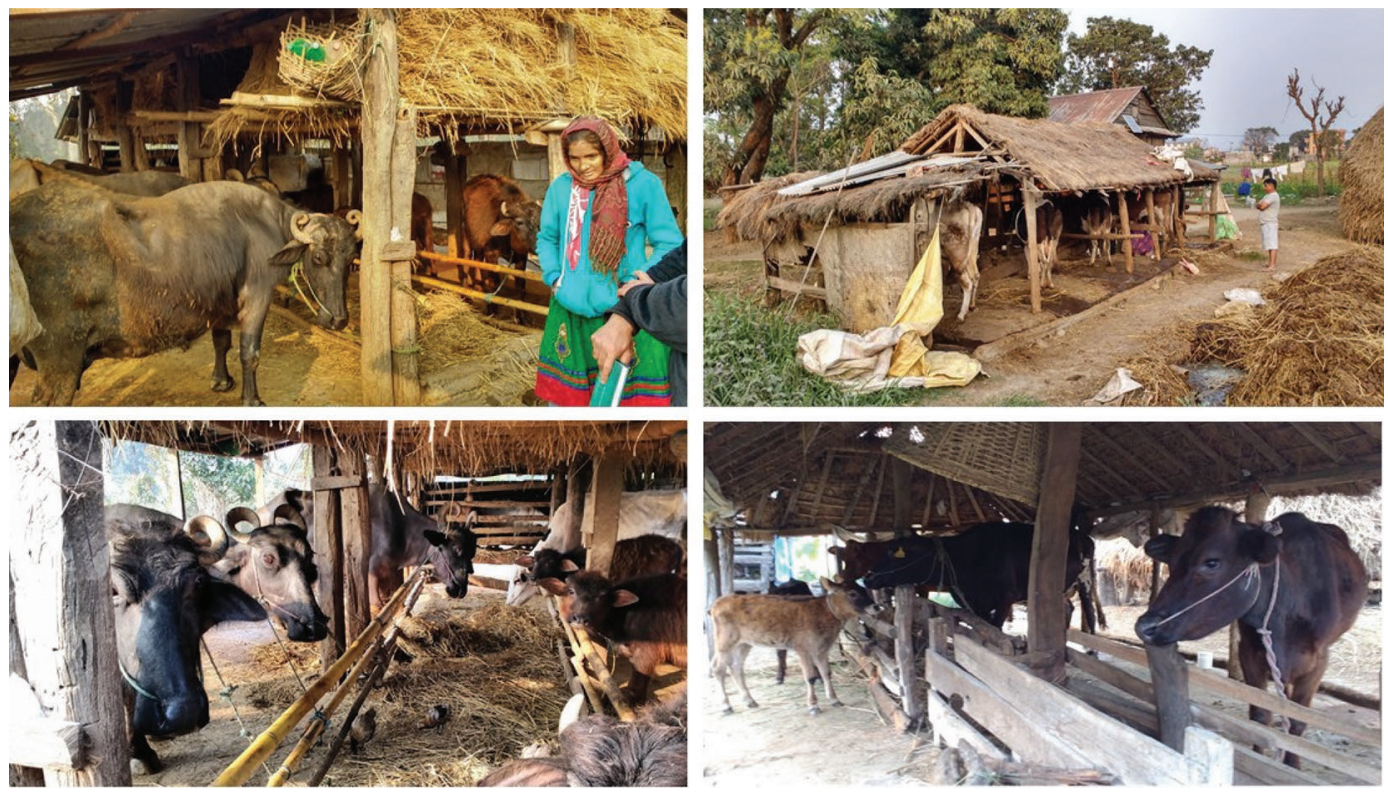

Figure A5. Cattle and buffalo housing near Chitwan, Nepal. Photographs taken during the rapid needs assessment in Nepal (courtesy of K. E. Kaylegian and A. De Vries). 

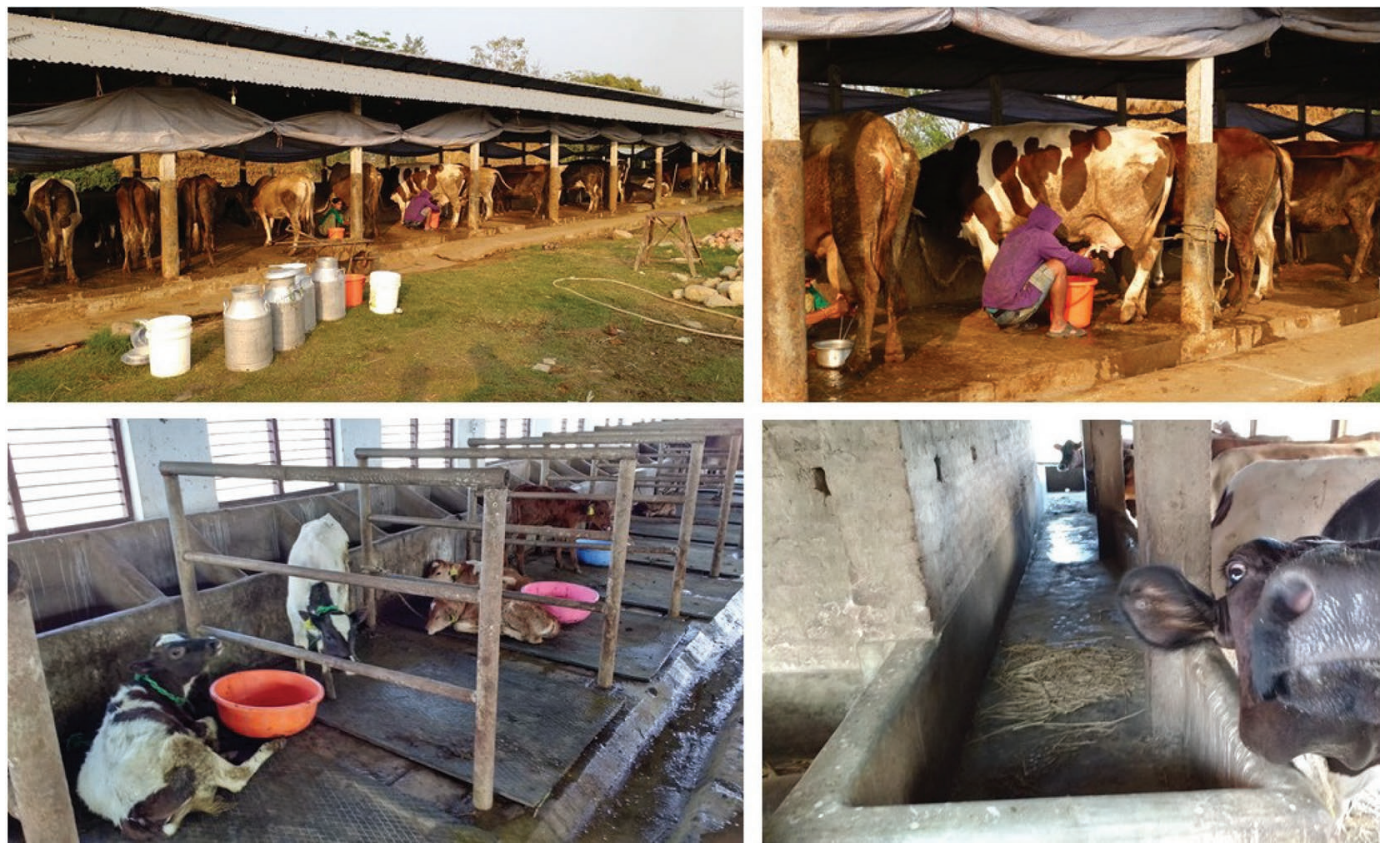

Figure A6. Milking cows near Chitwan, Nepal (top). Housing conditions near Chitwan, Nepal (bottom). Photographs taken during the rapid needs assessment in Nepal (courtesy of K. E. Kaylegian and A. De Vries).
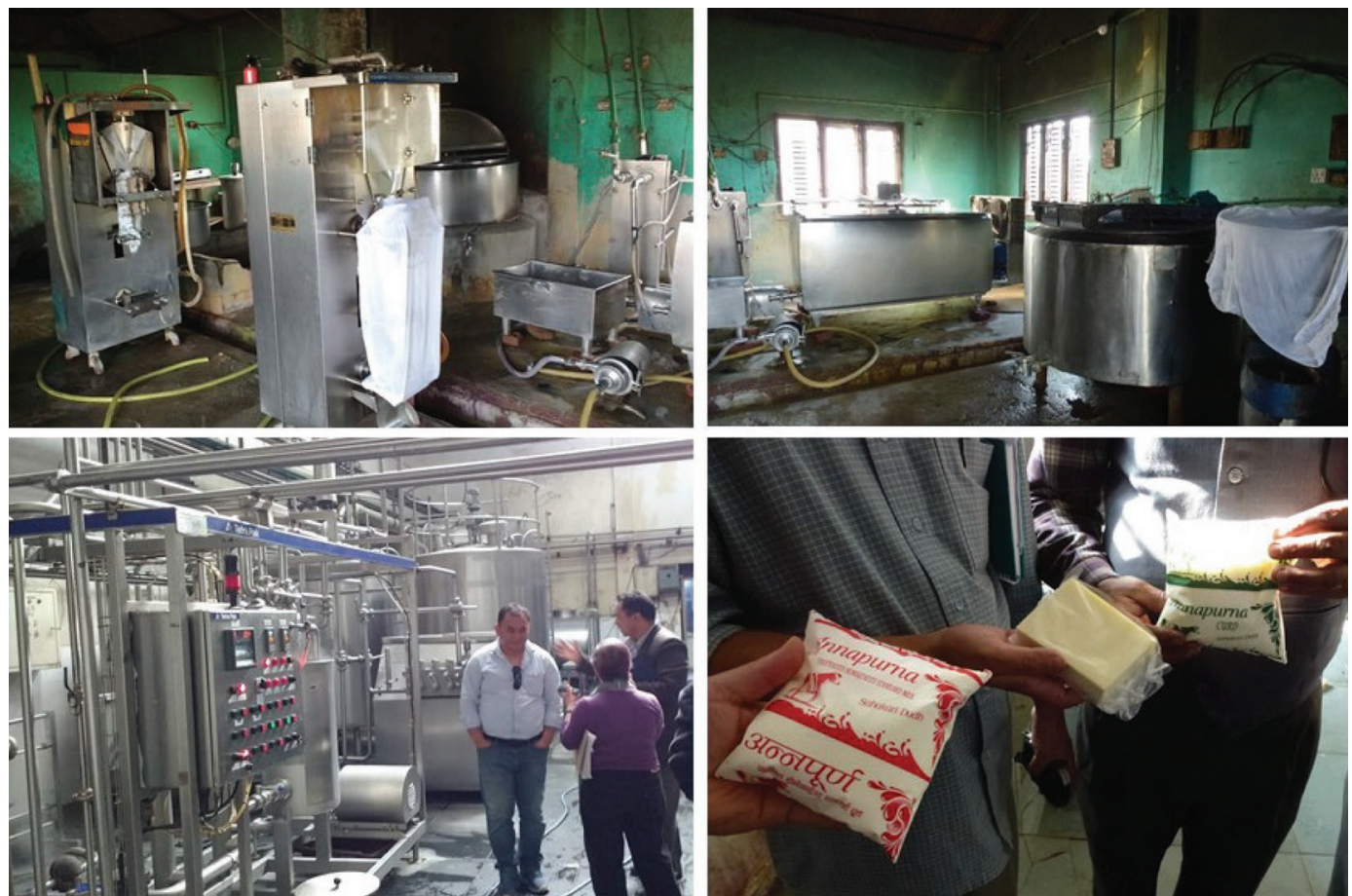

Figure A7. Processing equipment at dairy plant near Chitwan, Nepal (top). Processing equipment at dairy plant in Kathmandu, Nepal (bottom left). Milk, curd (yogurt), and ghee made at dairy processing plant near Chitwan, Nepal (bottom right). Photographs taken during the rapid needs assessment in Nepal (courtesy of K. E. Kaylegian and A. De Vries). 
APPENDIX 3

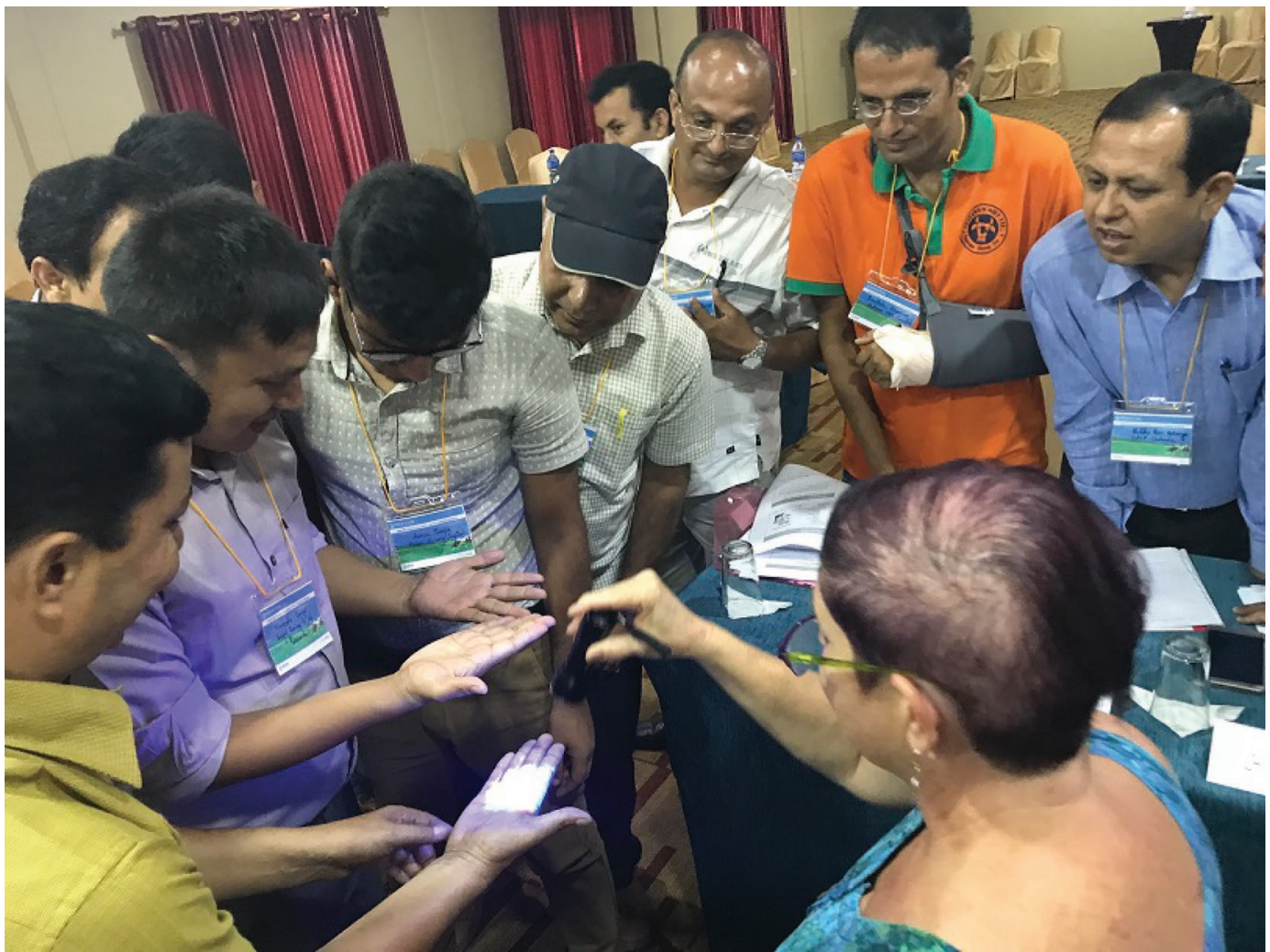

Figure A8. Handwashing demonstration in Chitwan, Nepal, during a training-of-trainers workshop (courtesy of Lisa Caprera, The Pennsylvania State University). 